\title{
Article \\ Seroprevalence of SARS-CoV-2 Antibodies in Adults and Healthcare Workers in Southern Italy
}

\author{
Francesco Napolitano ${ }^{1}(0)$, Gabriella Di Giuseppe ${ }^{1}$, , Maria Vittoria Montemurro ${ }^{2}$, Anna Maria Molinari ${ }^{3}$, \\ Giovanna Donnarumma ${ }^{1}$ (D) Antonio Arnese ${ }^{1}$, Maria Pavia ${ }^{1}$ (D) and Italo Francesco Angelillo $1, *$ (D) \\ 1 Department of Experimental Medicine, University of Campania "Luigi Vanvitelli", Via L. Armanni, \\ 580138 Naples, Italy; francesco.napolitano2@unicampania.it (F.N.); \\ gabriella.digiuseppe@unicampania.it (G.D.G.); giovanna.donnarumma@unicampania.it (G.D.); \\ antonio.arnese@unicampania.it (A.A.); maria.pavia@unicampania.it (M.P.) \\ 2 Health Direction, Teaching Hospital of the University of Campania "Luigi Vanvitelli", \\ Via Santa Maria di Costantinopoli, 10480138 Naples, Italy; mv.montemurro@libero.it \\ 3 Department of Precision Medicine, University of Campania "Luigi Vanvitelli", Via L. De Crecchio, \\ 780138 Naples, Italy; annamaria.molinari@unicampania.it \\ * Correspondence: italof.angelillo@unicampania.it; Tel.: +39-081-566-7717
}

\section{check for} updates

Citation: Napolitano, F.; Di Giuseppe, G.; Montemurro, M.V.; Molinari, A.M.; Donnarumma, G.; Arnese, A.; Pavia, M.; Angelillo, I.F. Seroprevalence of SARS-CoV-2 Antibodies in Adults and Healthcare Workers in Southern Italy. Int. J. Environ. Res. Public Health 2021, 18, 4761. https://doi.org/10.3390/ ijerph18094761

Academic Editor: Amal K. Mitra

Received: 26 March 2021

Accepted: 26 April 2021

Published: 29 April 2021

Publisher's Note: MDPI stays neutral with regard to jurisdictional claims in published maps and institutional affiliations.

Copyright: (c) 2021 by the authors. Licensee MDPI, Basel, Switzerland. This article is an open access article distributed under the terms and conditions of the Creative Commons Attribution (CC BY) license (https:// creativecommons.org/licenses/by/ $4.0 /)$
Abstract: Background: This study was carried out to estimate the seroprevalence of SARS-CoV-2 antibodies in a Southern Italian population. Methods: The study was performed among students and workers of the University of Campania "Luigi Vanvitelli" and the relative Teaching Hospital. Participants were invited to undergo a blood sampling, an interview or to complete a self-administered questionnaire. Results: A total of 140 participants (5.8\%) tested positive for SARS-CoV-2 antibodies. Positive SARS-CoV-2 test results increased significantly during the months of testing, and those who had had at least one symptom among fever, cough, dyspnea, loss of taste or smell and who had had contact with a family member/cohabitant with confirmed COVID-19 were more likely to test positive. Faculty members were less likely to have a positive test result compared to the healthcare workers (HCWs). Among HCWs, physicians showed the lowest rate of seroconversion (5.2\%) compared to nurses $(8.9 \%)$ and other categories $(10 \%)$. Nurses and other HCWs compared to the physicians, those who had had at least one symptom among fever, cough, dyspnea, loss of taste or smell, and who had had contact with a family member/cohabitant with confirmed COVID-19 were more likely to test positive. Conclusions: The results have demonstrated that SARS-CoV-2 infection is rapidly spreading even in Southern Italy and confirm the substantial role of seroprevalence studies for the assessment of SARS-CoV-2 infection circulation and potential for further spreading.

Keywords: adults; healthcare workers; Italy; SARS-CoV-2 antibodies; seroprevalence

\section{Introduction}

The surveillance of the occurrence of COVID-19 cases is substantially based on the diagnostic tests using reverse transcriptase polymerase chain reaction (RT-PCR) that are provided to symptomatic patients, to contacts of COVID-19 cases, and, in certain circumstances, to asymptomatic subjects with specific characteristics, such as healthcare workers (HCWs). Since it has been shown that asymptomatic infections occur very frequently [1-3], and that these subjects and those pre-symptomatic can spread the infection [4-6], surveillance data on COVID-19 cases appear to be inadequate to picture the extent and to limit the spread of severe acute respiratory syndrome coronavirus 2 (SARS-CoV-2) circulation within populations. Moreover, comprehensive data on the burden of SARS-CoV-2 infection would be essential for the calculation of the infection fatality rate related to this novel coronavirus $[7,8]$, and may also shed light on factors involved in the transmission among asymptomatic subjects.

Therefore, the availability of valid and reliable serologic tests for the detection of antibodies against SARS-CoV-2 has prompted the conduction of several epidemiological studies 
worldwide with the aim of estimating their prevalence in different populations [9-12], settings [13-15] and high-risk subjects, such as patients with underlying clinical conditions and HCWs [16-18].

In Italy, the initial course of the epidemic has determined an extraordinary and rapid development of the number of cases and deaths, characterized by a difference in the incidence between Northern and Southern regions, which suggested hypotheses involving demographic, geographic and genetic perspectives [19]. Instead, during the so called "second wave" of the pandemic, Southern regions have experienced an exponential increase in new COVID-19 cases starting from September 2020. To control the new massive spread of the SARS-CoV-2 infection, the Italian Government has promoted new restrictive measures, classifying the Regions into four areas (red, orange, yellow, white) according to the level of risk of infection. The measures for the containment of the epidemiological emergency include the limitation of travel and free circulation of persons, a night curfew, and the closure of urban spaces, sports facilities, schools and non-essential commercial activities according to the level of risk of infection periodically calculated in the Regions [20].

Despite these measures, the number of COVID-19 cases and deaths has increased dramatically and, to the best of our knowledge, up to date information on the proportion of subjects that have been infected and have produced antibodies against SARS-CoV-2 in Southern Italy is lacking [21-25], and it is reasonable to presume that a larger proportion of the population has been infected.

Therefore, this study was carried out to estimate, by measuring the seroprevalence of SARS-CoV-2 antibodies, the extent of the circulation of SARS-CoV-2 in an adult population and in HCWs in Southern Italy and to evaluate which socio-demographic, anamnestic, and professional characteristics might predict the risk of infection by SARS-CoV-2 in these populations.

\section{Materials and Methods}

\subsection{Study Design, Population Recruitment and Procedures}

The study was performed between 21 September 2020 and 31 December 2020, and it was part of a large project developed by the University of Campania "Luigi Vanvitelli" and the relative Teaching Hospital $[26,27]$ in order to guarantee the safety of patients, HCWs, and the overall university community who accessed the healthcare and university facilities. The study population consisted of participants: (1) who were in contact with patients such as HCWs and medical students; (2) who were not in contact with patients, but with HCWs, such as technicians, laboratory assistants, custodians, cleaners, and administrative staff of the Teaching Hospital; (3) non-medical students, faculty members, research fellows and administrative staff of non-medical University Departments.

The data collection process has been described in previous research [26]. Briefly, students and workers who attended the University and Hospital facilities received an invitation by email to be voluntarily tested for antibodies against SARS-CoV-2, and those who responded were invited to the Health Surveillance ambulatory centers located in Caserta and Naples to perform a blood sampling and to undergo a structured interview or, if they preferred, to complete a self-administered questionnaire.

In the waiting rooms of the ambulatory centers, the research team provided participants with the information about the study aims and the methods of data collection, and a signed consent form from each participant was obtained from those who were willing to participate. Prior to undergoing blood sampling, three well-trained investigators in data collection techniques invited the participants to undergo the interview or to complete the self-administered questionnaire.

\subsection{Survey Instrument}

The questionnaire consisted of two sections. In the first one, the questions concerned participants' socio-demographic (gender, age, marital status, education level), professional (professional role, whether they were HCWs, specific workplace and degree course (for 
students)), and anamnestic characteristics (weight and height, smoking status, presence and type of underlying clinical conditions, personal history of SARS-CoV-2 infection). In the second section, participants were asked whether they had been exposed to confirmed COVID-19 cases (cohabiting or non-cohabiting family members, friends, work or study colleagues, neighbors and patients), whether they had had COVID-19-compatible symptoms since February 2020 (headache, myalgia, fever, cough, dyspnea, tiredness, sore throat, nausea and vomiting, conjunctivitis, diarrhea, loss of taste or smell), whether they had been tested by RT-PCR for SARS-CoV-2 detection and the results of each testing, and the participants' travel history outside Italy since February 2020.

\subsection{Blood Sampling and Laboratory Methods}

The blood samples were collected using test tubes with separator polymer gel (BD Vacutainer ${ }^{\circledR} \mathrm{SST}^{\mathrm{TM}}$ Tubes) and, after centrifugation, sera were stored at $4{ }^{\circ} \mathrm{C}$ until analysis. The detection of antibodies was performed within $24 \mathrm{~h}$ from sample collection in three laboratories located in the Teaching Hospital, using the following three chemiluminescence enzyme immunoassay (CLIA) tests: (1) total antibodies including IgM, IgG and IgA against SARS-CoV-2 using the VITROS ECiQ Immunodiagnostic Systems ${ }^{\circledR}$ (Ortho-Clinical Diagnostics, Rochester, New York, NY, USA), an assay that employs luminol-horseradish peroxidase (HRP)-mediated chemiluminescence, with a sensitivity of $100 \%(95 \% \mathrm{CI}=$ $92.7-100 \%)$ and a specificity of $100 \%(95 \% \mathrm{CI}=99.1-100 \%)$; samples with signal to cut-off (S/C) greater than or equal to 1 were considered positive; (2) detection of IgM and IgG using Abbott ARCHITECT i2000SR Instrument (Abbott Diagnostics, Chicago, IL, USA), with sensitivity for IgM and IgG of $95 \%$ and $100 \%$, respectively, and specificity for IgM and IgG of $99.1 \%$ and $99.9 \%$, respectively; samples with signal to cut-off (S/C) greater than or equal to 1.4 were considered positive; and (3) detection of IgM and S1/S2 IgG using LIAISON ${ }^{\circledR}$ SARS-CoV-2 IgM qualitative test and S1/S2 IgG quantitative test (DiaSorin S.p.A., Saluggia, Italy), with a combined sensitivity of $98.3 \%(95 \% \mathrm{CI}=93.9-99.5 \%)$ and a specificity of $99.2 \%$ $(95 \% \mathrm{CI}=98-99.7 \%)$; results above or equal to the 1.10 index indicated the presence of IgM antibodies against SARS-CoV-2 and samples with $\mathrm{S} 1 / \mathrm{S} 2 \mathrm{IgG}>15.0 \mathrm{AU} / \mathrm{mL}$ were considered positive. All tests were performed according to the manufacturer's instructions.

Subjects who tested positive for SARS-CoV-2 antibodies were invited to voluntarily undergo RT-PCR for SARS-CoV-2 detection from nasopharyngeal swabs.

\subsection{Statistical Analysis}

A descriptive analysis has been performed to describe the socio-demographic, professional and anamnestic characteristics of the participants overall and according to SARS$\mathrm{CoV}-2$ antibodies positivity. A bivariate analysis was carried out to evaluate the effect of the independent variables on the seropositivity for antibodies against SARS-CoV-2 in the overall sample and restricted to the group of HCWs using a chi-square test or Fisher's exact test for the categorical variables and a Student's t-test for the continuous variables. Then, a multivariate stepwise logistic regression analysis was performed to investigate the association of each independent variable with positivity for SARS-CoV-2 antibodies (Model 1$)$, and the following variables were included: age (18-39 years $=1 ; 40-59$ years $=2$; $\geq 60$ years $=3$ ), gender ( male $=0$; female $=1$ ), education level (high school degree or less $=0$; college degree or higher $=1$ ), marital status (unmarried $/$ widowed $/$ separated $/$ divorced $=0$; married $/$ cohabiting $=1)$, population group $(\mathrm{HCWs}=1$; faculty members $=2$; students $=3$; research fellows $=4$; administrative staff $=5$; biologists $/$ technicians $=6$; other $=7$ ), current smoking $($ no $=0$; yes $=1)$, body mass index $(\mathrm{BMI})$ (underweight $/$ normal weight $=0$; overweight / obese $=1)$, having at least one chronic medical condition $($ no $=0$; yes $=1)$, travel history outside Italy in the previous ten months (no $=0$; yes $=1)$, number of contacts with a confirmed COVID-19 case (none $=0 ; 1=1 ; 2=2 ;>2=3$ ), contact with confirmed COVID-19 co-workers/study colleagues (no $=0$; yes $=1$ ), contact with confirmed COVID-19 family members / cohabitants $($ no $=0$; yes $=1)$, having had at least one symptom among fever, cough, dyspnea, loss of taste or smell in the previous ten months (no = 0 ; yes $=1)$, and 
month of testing (September $=1$; October $=2$; November $=3$; December $=4$ ). The same model was performed after restriction to the HCWs group with the addition of the following variables: contact with confirmed COVID-19 patients $($ no $=0$; yes $=1)$, professional role ( physicians $=1$; nurses $=2$; other (nurse assistants, technicians, laboratory assistants) $=3$ ), working in wards where aerosol-producing procedures are performed (no = 0; yes $=1$ ), and current working area (critical care/COVID-19 units $=1$; medical $=2$; surgical = 3; laboratory and diagnostics $=4)($ Model 2).

Significance levels for exclusion and inclusion of variables in the models were $p$-values of 0.4 and 0.2 , respectively. The results of the logistic regression analyses were reported as odds ratios (ORs) and 95\% confidence intervals (CIs). All inferential tests were two-tailed with significant statistical levels for $p$-values equal to or less than 0.05 . The statistical software Stata 15 [28] was used to carry out the analysis.

\section{Results}

A total of 2394 subjects voluntarily agreed to participate in the SARS-CoV-2 antibodies testing program. Table 1 displays the demographic, professional and anamnestic characteristics of the participants and the associated positivity for SARS-CoV-2 antibodies. More than one third (35.9\%) were HCWs, 30.2\% students, $17.3 \%$ administrative workers and $9.1 \%$ were faculty members. One in five reported to have at least one chronic disease (19.5\%), and the most frequent were cardiovascular (30.8\%), autoimmune $(22.3 \%)$, allergies $(21.6 \%)$ and respiratory diseases (15.4\%), while 5.3\% of the participants had diabetes. Almost one fifth (19.8\%) had had contact with a confirmed COVID-19 case, 1.7\% reported having contracted COVID-19, 515 (21.5\%) had had COVID-19-compatible symptoms and 11.4\% at least one symptom among fever, cough, dyspnea and loss of taste or smell from the beginning of the spread of the SARS-CoV-2 in Italy.

Overall, 140 participants (5.8\%) tested positive for SARS-CoV-2 antibodies; specifically, $128(84.2 \%)$ were positive for both $\operatorname{IgM}$ and $\operatorname{IgG}, 11(7.9 \%)$ were $\operatorname{IgM}+\operatorname{IgG}^{-}$, and $11(7.9 \%)$ were $\operatorname{IgM}-\mathrm{IgG}+$, with a statistically significant time trend from September $(2.9 \%)$ to December $(8.7 \%)\left(\chi^{2}=11.41, p<0.001\right)$. Of the 140 seropositive subjects, $98(70 \%)$ voluntarily underwent nasopharyngeal swabs for RT-PCR SARS-CoV-2 detection, and four (4.1\%) were diagnosed as COVID-19 cases.

Although not significantly, HCWs had the highest positive rate (7.1\%), followed by biologists/technicians (6.6\%), administrative staff (6.3\%) and students (5.5\%). Overall, among those who were not HCWs and non-medical students, 5.2\% were positive to SARSCoV-2 antibodies. Moreover, $26.4 \%$ of those who tested positive had had a close contact with confirmed COVID-19 cases, $26.4 \%$ were active smokers, and one in five (19.3\%) had at least one chronic disease. At the bivariate analysis, the seroprevalence was significantly higher among participants who had had contacts with a confirmed COVID-19 case $(7.8 \%$ vs. $\left.5.4 \% ; \chi^{2}=4.11, p=0.04\right)$, and specifically with family members / cohabitants $(22.2 \%$ vs. $\left.5.4 \% ; \chi^{2}=31.5, p<0.001\right)$, those reporting COVID-19-compatible symptoms $(9.5 \%$ vs. $4.9 \%$; $\left.\chi^{2}=16.02, p<0.001\right)$, or at least one symptom among fever, cough, dyspnea and loss of taste or smell $\left(12.8 \%\right.$ vs. $\left.4.9 \% ; \chi^{2}=26.95, p<0.001\right)$ from the beginning of the spread of the SARS-CoV-2 infection.

Most of these results were confirmed after adjustment through the multivariate logistic regression analysis, that showed that positive SARS-CoV-2 tests increased significantly during the months of testing $(\mathrm{OR}=1.4 ; 95 \% \mathrm{CI}=1.13-1.74)$. Moreover, participants who had had at least one symptom among fever, cough, dyspnea, loss of taste or smell in the previous ten months $(\mathrm{OR}=2.98 ; 95 \% \mathrm{CI}=1.94-4.56)$ and those who had had contact with a family member/cohabitant with confirmed COVID-19 $(\mathrm{OR}=8.58$; 95\% CI $=2.14-34.34)$ were more likely to test positive for SARS-CoV-2 antibodies. Instead, faculty members were less likely to have a positive test result compared to the HCWs $(\mathrm{OR}=0.3 ; 95 \% \mathrm{CI}=$ 0.12-0.76) (Model 1 in Table 2). The significant association between having had at least one symptom among fever, cough, dyspnea, loss of taste or smell and the positivity to SARS-CoV-2 antibodies persisted also after the exclusion from the analysis of participants 
with a COVID-19 diagnosis before the study (OR $=1.83 ; 95 \% \mathrm{CI}=1.08-3.1)$ (data not shown).

Table 1. Demographic, professional and anamnestic characteristics of the participants and the associated positivity to SARS-CoV-2 antibodies.

\begin{tabular}{|c|c|c|c|c|}
\hline \multirow[t]{2}{*}{ Characteristic } & \multicolumn{2}{|c|}{$\begin{array}{c}\text { Overall Population } \\
n=2394\end{array}$} & \multicolumn{2}{|c|}{$\begin{array}{c}\text { SARS-CoV-2 Antibody Positive } \\
n=140\end{array}$} \\
\hline & $n$ & $\%$ & $n$ & $\%$ \\
\hline \multicolumn{5}{|l|}{ Gender } \\
\hline Female & 1423 & 59.4 & 83 & 5.9 \\
\hline \multirow[t]{2}{*}{ Male } & 971 & 40.6 & 57 & 5.8 \\
\hline & & & \multicolumn{2}{|c|}{$\chi^{2}=0.001 ; p=0.969$} \\
\hline \multicolumn{5}{|l|}{ Age, years } \\
\hline $18-39$ & 1446 & 60.4 & 89 & 6.1 \\
\hline $40-59$ & 735 & 30.7 & 42 & 5.7 \\
\hline \multirow{2}{*}{$\geq 60$} & 213 & 8.9 & 9 & 4.2 \\
\hline & & & \multicolumn{2}{|c|}{$\chi^{2}=1.29 ; p=0.525$} \\
\hline \multicolumn{5}{|l|}{ Education level } \\
\hline College degree or higher & 1486 & 62.1 & 88 & 5.9 \\
\hline High school degree or less & 908 & 37.9 & 52 & 5.7 \\
\hline & & & \multicolumn{2}{|c|}{$\chi^{2}=0.039 ; p=0.844$} \\
\hline \multicolumn{5}{|l|}{ Marital status } \\
\hline Unmarried/widowed/separated/divorced & 1484 & 62 & 89 & 6 \\
\hline \multirow[t]{2}{*}{ Married/cohabiting } & 910 & 38 & 51 & 5.6 \\
\hline & & & \multicolumn{2}{|c|}{$\chi^{2}=0.158 ; p=0.691$} \\
\hline \multicolumn{5}{|c|}{$x-0.100, p-0.071$} \\
\hline Overweight/obese & 860 & 35.9 & 54 & 6.3 \\
\hline Under/normal weight & 1534 & 64.1 & 86 & 5.7 \\
\hline & & & \multicolumn{2}{|c|}{$\chi^{2}=0.453 ; p=0.501$} \\
\hline \multicolumn{5}{|l|}{ Current smoking } \\
\hline Yes & 582 & 24.3 & 37 & 6.4 \\
\hline \multirow[t]{2}{*}{ No } & 1812 & 75.7 & 103 & 5.7 \\
\hline & & & \multicolumn{2}{|c|}{$\chi^{2}=0.362 ; p=0.547$} \\
\hline \multicolumn{5}{|l|}{ Having at least one chronic medical condition } \\
\hline Yes & 468 & 19.5 & 27 & 5.8 \\
\hline \multirow[t]{2}{*}{ No } & 1926 & 80.5 & 113 & 5.9 \\
\hline & & & $x^{2}$ & 963 \\
\hline Population group & & & & \\
\hline HCWs & 859 & 35.9 & 61 & 7.1 \\
\hline Biologists/Technicians & 76 & 3.2 & 5 & 6.6 \\
\hline Administrative staff & 415 & 17.3 & 26 & 6.3 \\
\hline Students & 723 & 30.2 & 40 & 5.5 \\
\hline Other & 67 & 2.8 & 2 & 3 \\
\hline Research fellows & 36 & 1.5 & 1 & 2.8 \\
\hline Faculty members & 218 & 9.1 & 5 & 2.3 \\
\hline & & & Fishe & 0.137 \\
\hline Travel history outside Italy in the previous $10 \mathrm{mo}$ & & & & \\
\hline Yes & 190 & 7.9 & 16 & 8.4 \\
\hline No & 2204 & 92.1 & 124 & 5.6 \\
\hline & & & $x^{2}$ & \\
\hline COVID-19 diagnosis before study & & & & \\
\hline Yes & 40 & 1.7 & 30 & 75 \\
\hline No & 2354 & 98.3 & 110 & 4.7 \\
\hline & & & $x^{2}=$ & 001 \\
\hline Contact with a confirmed COVID-19 case & & & & \\
\hline Yes & 474 & 19.8 & 37 & 7.8 \\
\hline No & 1920 & 80.2 & 103 & 5.4 \\
\hline & & & $x^{2}$ & \\
\hline
\end{tabular}


Table 1. Cont.

\begin{tabular}{|c|c|c|c|c|}
\hline \multirow[t]{2}{*}{ Characteristic } & \multicolumn{2}{|c|}{$\begin{array}{c}\text { Overall Population } \\
n=2394\end{array}$} & \multicolumn{2}{|c|}{$\begin{array}{c}\text { SARS-CoV-2 Antibody Positive } \\
\qquad n=140\end{array}$} \\
\hline & $n$ & $\%$ & $n$ & $\%$ \\
\hline \multicolumn{5}{|c|}{ Number of contacts with a confirmed COVID-19 case ${ }^{\wedge}$} \\
\hline$>2$ & 51 & 10.8 & 5 & 9.8 \\
\hline 2 & 95 & 20 & 9 & 9.5 \\
\hline 1 & 328 & 69.2 & 23 & 7 \\
\hline & & & \multicolumn{2}{|c|}{ Fisher's exact $p=0.589$} \\
\hline \multicolumn{5}{|c|}{ Contact(s) with confirmed COVID-19 co-workers/study colleagues } \\
\hline Yes & 368 & 15.4 & 24 & 6.5 \\
\hline No & 2026 & 84.6 & 13 & 5.7 \\
\hline & & & \multicolumn{2}{|c|}{$\chi^{2}=0.34 ; p=0.559$} \\
\hline \multicolumn{5}{|c|}{ Contact(s) with confirmed COVID-19 family members/cohabitants } \\
\hline Yes & 63 & 2.6 & 14 & 22.2 \\
\hline \multirow[t]{2}{*}{ No } & 2331 & 97.4 & 126 & 5.4 \\
\hline & & & \multicolumn{2}{|c|}{$\chi^{2}=31.5 ; p<0.001$} \\
\hline \multicolumn{5}{|c|}{$\begin{array}{l}\text { Having had at least one COVID-19-compatible symptom in the } \\
\text { previous ten months }\end{array}$} \\
\hline Yes & 515 & 21.5 & 49 & 9.5 \\
\hline \multirow[t]{2}{*}{ No } & 1879 & 78.5 & 91 & 4.9 \\
\hline & & & \multicolumn{2}{|c|}{$\chi^{2}=16.02 ; p<0.001$} \\
\hline \multicolumn{5}{|c|}{$\begin{array}{l}\text { Having had at least one symptom among fever, cough, dyspnea, } \\
\text { loss of taste or smell in the previous ten months }\end{array}$} \\
\hline Yes & 274 & 11.4 & 35 & 12.8 \\
\hline \multirow[t]{2}{*}{ No } & 2120 & 88.6 & 105 & 4.9 \\
\hline & & & \multicolumn{2}{|c|}{$\chi^{2}=26.95 ; p<0.001$} \\
\hline \multicolumn{5}{|c|}{$\begin{array}{l}\text { Having undergone at least one screening test with RT-PCR for } \\
\text { SARS-CoV-2 detection in the previous ten months }\end{array}$} \\
\hline Yes & 1111 & 46.4 & 71 & 6.4 \\
\hline \multirow[t]{2}{*}{ No } & 1283 & 53.6 & 69 & 5.4 \\
\hline & & & \multicolumn{2}{|c|}{$\chi^{2}=1.108 ; p=0.292$} \\
\hline \multicolumn{5}{|l|}{ Month of testing } \\
\hline December & 127 & 5.3 & 11 & 8.7 \\
\hline November & 752 & 31.4 & 56 & 7.5 \\
\hline October & 1110 & 46.4 & 61 & 5.5 \\
\hline September & 405 & 16.9 & 12 & 2.9 \\
\hline & & & \multicolumn{2}{|c|}{$\chi^{2}$ trend $=11.41 ; p<0.001$} \\
\hline
\end{tabular}

Table 3 reports the descriptive and univariate analysis restricted to HCWs. Within this subgroup, which, as mentioned, showed the highest seroprevalence of SARS-CoV-2 antibodies, physicians were the professional category that showed the lowest rate of seroconversion $(5.2 \%)$, compared to nurses $(8.9 \%)$ and other categories of HCWs $(10 \%)$, and these differences almost achieved statistical significance $\left(\chi^{2}=5.95, p=0.051\right)$. Seroprevalence also differed, although not significantly, according to hospital area, ranging from $5.9 \%$ in HCWs attending the medical wards to $8.3 \%$ in those working in the critical care/COVID19 units, and even for HCWs, contacts with COVID-19 family members/cohabitants were significantly associated to positivity to SARS-CoV-2 antibodies. Of the 40 reported COVID19 cases, $33(82.5 \%)$ were HCWs; specifically, $15(45.4 \%)$ were physicians, $12(26.4 \%)$ nurses and $6(18.2 \%)$ other HCWs (nurse assistants, technicians, laboratory assistants). For the other tested characteristics, compared to the overall population, no relevant differences were found at the univariate analysis.

In the logistic regression model investigating associations with positivity to SARS-CoV2 antibodies in HCWs the results confirmed that nurses ( $\mathrm{OR}=2.1 ; 95 \% \mathrm{CI}=1.07-4.13)$ and other HCWs, including nurse assistants, technicians and laboratory assistants $(\mathrm{OR}=2.57$; $95 \% \mathrm{CI}=1.29-5.14)$, compared to the physicians, had a significantly higher probability of testing positive for SARS-CoV-2 antibodies, as well as those who had had at least 
one symptom among fever, cough, dyspnea, loss of taste or smell $(\mathrm{OR}=4.47 ; 95 \% \mathrm{CI}$ $=2.25-8.89)$, and those who had had contact with a family member/cohabitant with confirmed COVID-19 (OR = 8.5; 95\% CI = 1.74-41.5) (Model 2 in Table 2). When HCWs with a COVID-19 diagnosis before study were excluded from the logistic regression analysis, having had at least one symptom among fever, cough, dyspnea, loss of taste or smell was no more significantly associated to positivity to SARS-CoV-2 antibodies (data not shown).

Table 2. Results of multivariate logistic regression analysis investigating the factors associated with positivity to SARS-CoV-2 antibodies.

\begin{tabular}{|c|c|c|c|c|}
\hline Variable & OR & SE & $95 \% \mathrm{CI}$ & $p$ \\
\hline \multicolumn{5}{|c|}{$\begin{array}{l}\text { Model 1. Positivity to SARS-CoV-2 antibodies (Sample size }=2394) \\
\text { Log likelihood }=-499.85, \chi^{2}=66.88(14 \mathrm{df}), p<0.0001\end{array}$} \\
\hline $\begin{array}{l}\text { Having had at least one symptom among fever, cough, dyspnea, } \\
\text { loss of taste or smell in the previous ten months }\end{array}$ & 2.98 & 0.65 & $1.94-4.56$ & $<0.001$ \\
\hline Contact(s) with confirmed COVID-19 family members/cohabitants & 8.58 & 6.07 & $2.14-34.34$ & 0.002 \\
\hline $\begin{array}{l}\text { Month of testing (September through December 2020) } \\
\text { Population group }\end{array}$ & 1.4 & 0.15 & $1.13-1.74$ & 0.002 \\
\hline HCWs & $1 *$ & & & \\
\hline Faculty member & 0.3 & 0.14 & $0.12-0.76$ & 0.011 \\
\hline Students & 0.66 & 0.14 & $0.43-1.01$ & 0.051 \\
\hline Research fellows & 0.36 & 0.37 & $0.05-2.75$ & 0.327 \\
\hline Other & 0.3 & 0.22 & $0.07-1.29$ & 0.107 \\
\hline Administrative staff & \multicolumn{4}{|c|}{ Backward elimination } \\
\hline Technicians/Biologists & \multicolumn{4}{|c|}{ Backward elimination } \\
\hline $\begin{array}{l}\text { Travel history outside Italy in the previous ten months } \\
\text { Number of contacts with a confirmed COVID-19 case }\end{array}$ & 1.69 & 0.49 & $0.96-2.98$ & 0.067 \\
\hline None & $1 *$ & & & \\
\hline 1 & 0.33 & 0.23 & $0.09-1.26$ & 0.107 \\
\hline 2 & 0.42 & 0.33 & $0.09-1.94$ & 0.266 \\
\hline$>2$ & 0.29 & 0.28 & $0.04-1.99$ & 0.209 \\
\hline $\begin{array}{l}\text { Contact(s) with confirmed COVID-19 co-workers/study colleagues } \\
\text { Age }\end{array}$ & 2.45 & 1.71 & $0.63-9.53$ & 0.196 \\
\hline $18-39$ years & $1 *$ & & & \\
\hline$>59$ years & 0.64 & 0.24 & $0.31-1.32$ & 0.233 \\
\hline $40-59$ years & \multirow{2}{*}{\multicolumn{4}{|c|}{ Backward elimination }} \\
\hline BMI & & & & \\
\hline Under/normal weight & $1^{*}$ & & & \\
\hline Overweight/obese & 1.23 & 0.23 & $0.85-1.77$ & 0.264 \\
\hline \multicolumn{5}{|c|}{$\begin{array}{l}\text { Model 2. Positivity for SARS-CoV-2 antibodies among HCWs (Sample size = 859) } \\
\text { Log likelihood }=-194.17, \chi^{2}=51.89(12 \mathrm{df}), p<0.0001\end{array}$} \\
\hline $\begin{array}{l}\text { Having had at least one symptom among fever, cough, dyspnea, } \\
\text { loss of taste or smell in the previous ten months }\end{array}$ & 4.47 & 1.57 & $2.25-8.89$ & $<0.001$ \\
\hline Month of testing (September through December 2020) & 1.65 & 0.27 & $1.19-2.28$ & 0.003 \\
\hline \multicolumn{5}{|l|}{ Professional role } \\
\hline Physicians & $1 *$ & & & \\
\hline Nurses & 2.1 & 0.73 & $1.07-4.13$ & 0.032 \\
\hline Other (nurse assistants, technicians, laboratory assistants) & 2.57 & 0.9 & $1.29-5.14$ & 0.007 \\
\hline $\begin{array}{c}\text { Contact(s) with confirmed COVID-19 family members/cohabitants } \\
\text { Age }\end{array}$ & 8.5 & 6.87 & $1.74-41.5$ & 0.008 \\
\hline $18-39$ years & $1 *$ & & & \\
\hline $40-59$ years & 0.56 & 0.19 & $0.28-1.09$ & 0.086 \\
\hline$>59$ years & 0.59 & 0.28 & $0.23-1.51$ & 0.276 \\
\hline Male HCWs & 0.63 & 0.18 & $0.36-1.11$ & 0.109 \\
\hline \multicolumn{5}{|l|}{ Number of contacts with a confirmed COVID-19 case } \\
\hline None & $1 *$ & & & \\
\hline 1 & 0.37 & 0.29 & $0.08-1.71$ & 0.205 \\
\hline 2 & 0.45 & 0.41 & $0.07-2.72$ & 0.385 \\
\hline$>2$ & 0.38 & 0.4 & $0.05-3.05$ & 0.365 \\
\hline Contact(s) with confirmed COVID-19 co-workers & 2.18 & 1.72 & $0.46-10.22$ & 0.325 \\
\hline
\end{tabular}

${ }^{*}$ Reference category. The following variables were removed from the models by the backward elimination procedure: gender, marital status, education level, current smoker and having at least one chronic medical condition (Model 1); marital status, education level, BMI, having at least one chronic medical condition, current working area, working in wards where aerosol-producing procedures are performed and travel history outside Italy in the previous ten months (Model 2). 
Table 3. Demographic, professional and anamnestic characteristics of the HCWs and the associated positivity to SARS-CoV-2 antibodies.

\begin{tabular}{|c|c|c|c|c|}
\hline \multirow[t]{2}{*}{ Characteristic } & \multicolumn{2}{|c|}{$\begin{array}{l}\text { Overall Population } \\
\qquad n=859\end{array}$} & \multicolumn{2}{|c|}{$\begin{array}{l}\text { SARS-CoV-2 Antibody Positive } \\
\qquad n=61\end{array}$} \\
\hline & $n$ & $\%$ & $n$ & $\%$ \\
\hline \multicolumn{5}{|l|}{ Gender } \\
\hline Male & 367 & 42.7 & 31 & 8.4 \\
\hline \multirow[t]{2}{*}{ Female } & 492 & 57.3 & 30 & 6.1 \\
\hline & & & \multicolumn{2}{|c|}{$\chi^{2}=1.76 ; p=0.185$} \\
\hline \multicolumn{5}{|l|}{ Age, years } \\
\hline $18-39$ & 508 & 59.1 & 40 & 7.9 \\
\hline $40-59$ & 249 & 29 & 15 & 6 \\
\hline \multirow[t]{2}{*}{$\geq 60$} & 102 & 11.9 & 6 & 5.9 \\
\hline & & & \multicolumn{2}{|c|}{$\chi^{2}=1.13 ; p=0.569$} \\
\hline \multicolumn{5}{|l|}{ Education level } \\
\hline High school degree or less & 101 & 11.8 & 11 & 10.9 \\
\hline \multirow{2}{*}{ College degree or higher } & 758 & 88.2 & 50 & 6.6 \\
\hline & & & \multicolumn{2}{|c|}{$\chi^{2}=2.49 ; p=0.117$} \\
\hline \multicolumn{5}{|l|}{ Marital status } \\
\hline Unmarried/widowed/separated/divorced & 460 & 53.5 & 33 & 7.2 \\
\hline Married/cohabiting & 399 & 46.5 & 28 & 7 \\
\hline & & & \multicolumn{2}{|c|}{$\chi^{2}=0.16 ; p=0.691$} \\
\hline \multicolumn{5}{|c|}{ t } \\
\hline Overweight/obese & 309 & 36 & 24 & 7.8 \\
\hline Under/normal weight & 550 & 64 & 37 & 6.7 \\
\hline & & & \multicolumn{2}{|c|}{$\chi^{2}=2.22 ; p=0.329$} \\
\hline \multicolumn{5}{|l|}{ Current smoking } \\
\hline Yes & 241 & 28.1 & 14 & 5.8 \\
\hline No & 618 & 71.9 & 47 & 7.6 \\
\hline & & & \multicolumn{2}{|c|}{$\chi^{2}=0.36 ; p=0.547$} \\
\hline \multicolumn{5}{|l|}{ Professional role } \\
\hline Others (nurse assistants, technicians, laboratory assistants) & 170 & 19.8 & 17 & 10 \\
\hline Nurses & 224 & 26.1 & 20 & 8.9 \\
\hline \multirow[t]{2}{*}{ Physicians } & 465 & 54.1 & 24 & 5.2 \\
\hline & & & & \\
\hline Current working area & & & & \\
\hline Critical care/COVID-19 units & 108 & 12.6 & 9 & 8.3 \\
\hline Surgical & 260 & 30.3 & 21 & 8.1 \\
\hline Laboratory and Diagnostics & 121 & 14.1 & 9 & 7.4 \\
\hline Medical & 370 & 43.1 & 22 & 5.9 \\
\hline & & & & 07 \\
\hline Having at least one chronic medical condition & & & & \\
\hline Yes & 175 & 20.4 & 13 & 7.4 \\
\hline No & 684 & 79.6 & 48 & 7 \\
\hline & & & & \\
\hline Travel history outside Italy in the previous ten months & & & & \\
\hline Yes & 48 & 5.6 & 4 & 8.3 \\
\hline No & 811 & 94.4 & 57 & 7 \\
\hline & & & Fish & 0.769 \\
\hline COVID-19 diagnosis before study & & & & \\
\hline Yes & 33 & 3.8 & 24 & 72.7 \\
\hline No & 826 & 96.2 & 37 & 4.5 \\
\hline & & & & 001 \\
\hline Contact with a confirmed COVID-19 case & & & & \\
\hline Yes & 331 & 38.5 & 27 & 8.2 \\
\hline No & 528 & 61.5 & 34 & 6.5 \\
\hline & & & & 340 \\
\hline
\end{tabular}


Table 3. Cont.

\begin{tabular}{|c|c|c|c|c|}
\hline \multirow[t]{2}{*}{ Characteristic } & \multicolumn{2}{|c|}{$\begin{array}{l}\text { Overall Population } \\
\qquad n=859\end{array}$} & \multicolumn{2}{|c|}{$\begin{array}{l}\text { SARS-CoV-2 Antibody Positive } \\
\qquad n=61\end{array}$} \\
\hline & $n$ & $\%$ & $n$ & $\%$ \\
\hline \multicolumn{5}{|c|}{ Number of contacts with a confirmed COVID-19 case ${ }^{\wedge}$} \\
\hline$>2$ & 39 & 11.8 & 4 & 10.3 \\
\hline 2 & 70 & 21.1 & 6 & 8.6 \\
\hline \multirow[t]{2}{*}{1} & 222 & 67.1 & 17 & 7.7 \\
\hline & & & \multicolumn{2}{|c|}{ Fisher's exact $p=0.749$} \\
\hline \multicolumn{5}{|c|}{ Contact(s) with confirmed COVID-19 co-workers } \\
\hline Yes & 252 & 29.3 & 17 & 6.7 \\
\hline \multirow[t]{2}{*}{ No } & 607 & 70.7 & 44 & 7.2 \\
\hline & & & \multicolumn{2}{|c|}{$\chi^{2}=0.06 ; p=0.794$} \\
\hline \multicolumn{5}{|c|}{ Contact(s) with confirmed COVID-19 patients } \\
\hline Yes & 69 & 7.8 & 3 & 4.4 \\
\hline \multirow[t]{2}{*}{ No } & 790 & 92.2 & 58 & 7.3 \\
\hline & & & \multicolumn{2}{|c|}{ Fisher's exact $p=0.468$} \\
\hline \multicolumn{5}{|c|}{ Contact(s) with confirmed COVID-19 family members/cohabitants } \\
\hline Yes & 35 & 4.1 & 10 & 28.6 \\
\hline \multirow[t]{2}{*}{ No } & 824 & 95.9 & 51 & 6.2 \\
\hline & & & \multicolumn{2}{|c|}{ Fisher's exact $p<0.001$} \\
\hline \multicolumn{5}{|c|}{$\begin{array}{l}\text { Having had at least one COVID-19-compatible symptom in the } \\
\text { previous ten months }\end{array}$} \\
\hline Yes & 188 & 21.9 & 23 & 12.2 \\
\hline \multirow[t]{2}{*}{ No } & 671 & 78.1 & 38 & 5.7 \\
\hline & & & \multicolumn{2}{|c|}{$x^{2}=9.61 ; p=0.002$} \\
\hline \multicolumn{5}{|c|}{$\begin{array}{l}\text { Having had at least one symptom among fever, cough, dyspnea, } \\
\text { loss of taste or smell in the previous ten months }\end{array}$} \\
\hline Yes & 78 & 9.8 & 16 & 20.8 \\
\hline \multirow[t]{2}{*}{ No } & 781 & 90.2 & 45 & 5.7 \\
\hline & & & \multicolumn{2}{|c|}{$\chi^{2}=23.4 ; p<0.001$} \\
\hline \multicolumn{5}{|c|}{$\begin{array}{l}\text { Having undergone at least one screening test with RT-PCR for } \\
\text { SARS-CoV-2 detection in the previous ten months }\end{array}$} \\
\hline Yes & 782 & 91.1 & 49 & 6.3 \\
\hline \multirow[t]{2}{*}{ No } & 77 & 8.9 & 12 & 15.6 \\
\hline & & & \multicolumn{2}{|c|}{$\chi^{2}=9.23 ; p=0.002$} \\
\hline \multicolumn{5}{|l|}{ Month of testing } \\
\hline December & 94 & 10.9 & 10 & 10.6 \\
\hline November & 389 & 41.8 & 32 & 8.9 \\
\hline October & 229 & 26.7 & 14 & 6.1 \\
\hline \multirow[t]{2}{*}{ September } & 177 & 20.6 & 5 & 2.8 \\
\hline & & & \multicolumn{2}{|c|}{$\chi^{2}$ trend $=8.64 ; p=0.003$} \\
\hline
\end{tabular}

${ }^{\wedge}$ Among those who had had contact with a confirmed COVID-19 case.

\section{Discussion}

The present study reports the results of a comprehensive project that has investigated the circulation of the SARS-CoV-2 infection through the assessment of the seroprevalence of antibodies in a university population in Southern Italy. This is, to our knowledge, the first study analyzing the spread of the SARS-CoV-2 infection during the "second wave" of the pandemic, that has affected the southern regions of the country with a relevantly higher burden of cases and deaths compared to the first one.

The main finding of the study is that, in the period from September to December 2020, an overall anti-SARS-CoV-2 antibodies seroprevalence of 5.8\% was revealed in the investigated population, and that this circulation was time-dependent, with a remarkable trend ranging from $2.9 \%$ in September to $8.7 \%$ in December. These results stimulate a series of considerations on the course of the pandemic in this area and on the role of seroprevalence studies that deserve to be mentioned. First of all, they suggest that only the very early implementation of stringent public health control measures in Southern 
Italy, including the strict lockdown during the so called "first wave", that were established when the circulation of SARS-CoV-2 was still very low in the area, were able to contain the diffusion in Southern Italy, as revealed by a national seroprevalence study that showed a value less than $1 \%$ in Southern regions [29], whereas the milder measures implemented following the summer months were not so effective in the control of the SARS-CoV-2 spread during the "second wave", with an almost tripled prevalence in less than four months. An even faster spread has been reported in Switzerland over the course of a five-week study, with an increase in seroprevalence from 5\% to 11\% [11]. Moreover, the results suggest, consistent with previous studies $[9,10,24]$, that data on seroprevalence reflect a more realistic picture of the spread of the infection, that, also in this context, goes far beyond the results showed by the surveillance of confirmed COVID-19 cases, demonstrating the potentials for SARS-CoV-2 transmission through asymptomatic individuals.

Since previous seroprevalence studies differ, for example, in the involved populations, sample selection strategies and chosen laboratory tests, the comparability of results is hard to obtain, and the differences might be more related to study design and methodologies than to a variable SARS-CoV-2 circulation in the involved populations. Indeed, numerous studies have been conducted worldwide, and wide differences have been reported $(0.9-35.1 \%)[8,10,11,14,25,30]$. The results of two previous investigations conducted in a large geographic area of Northern Italy showed, as expected, higher rates of seropositivity, since $23 \%$ of blood donors [24] and $11 \%$ of non-hospitalized participants [25] had antibodies against SARS-CoV-2; instead, the seroprevalence was $0.99 \%$ in a sample of blood donors in a southern region [31]. Interestingly, in this investigation, 5.5\% of university students were positive for SARS-CoV-2 antibodies, and this rate is comparable with the result of $4 \%$ in a study conducted in the US on college students [32], whereas it was higher than that observed in Greek students (0.72\%) [15] and in Spain among a sample of students, faculty and administrative staff $(2.89 \%)$ [33]. Instead, higher seroprevalence rates were observed in Chile among students (9.9\%) and staff (16.6\%) [34] and in the US among campus students $(31.2 \%)$ [35]. No differences in SARS-CoV-2 seroprevalence were found according to several demographic characteristics, and this has already been reported in the literature $[9,30,36]$. Analogously, obesity and chronic diseases were not predictors of positivity to SARS-CoV-2 antibodies. However, many investigations have demonstrated that these conditions are associated with a high risk of severe complications and death from COVID-19 [37-40] and of symptomatic COVID-19, although the association to a higher susceptibility to SARSCoV2 is still controversial [41-45]. Further studies on the role of these conditions on the susceptibility to SARS-CoV-2 in asymptomatic subjects are warranted. The finding that close contacts with people with COVID-19, particularly those in the same household, is associated with increased odds of seroconversion, even in subjects that were not aware of having been infected, suggests that there has been a relevant number of individuals that were eligible for RT-PCR testing but have not undergone it. Missed opportunities for RT-PCR testing were also revealed by the finding that positivity to SARS-CoV-2 was significantly higher in those reporting COVID-19-compatible symptoms, showing that even symptomatic or pauci-symptomatic individuals did not receive diagnostic tests. The role of COVID-19-compatible symptoms as predictors of seropositivity has also been reported in other studies conducted in Italy, Europe and US $[8,9,25,32,46]$ and suggests that the surveillance of COVID-19 cases underestimated even the occurrence of symptomatic cases. It should also be remarked that the definition of the "asymptomatic" has been reported to be challenging and prone to limitations, since it is based on self-reported clinical symptoms and is evolving and conditioned by subjectivity [47].

As expected, the prevalence of SARS-CoV-2 antibodies was higher in HCWs (7.1\%) compared to all other investigated subgroups, and it is also worth noting that more than $80 \%$ of the reported COVID-19 cases were HCWs, confirming the occupational risk for both asymptomatic and symptomatic infections. This occurred even though the Teaching Hospital implemented all the recommended measures to limit the spread of the SARS-CoV2 infection (mandatory use of face masks, hand washing, distancing, etc.) and limited the 
access of visitors and caregivers. Furthermore, non-urgent surgical procedures have been postponed, and this has resulted in reductions in terms of surgical volume, diagnoses and hospitalizations [48-51]. Large differences in seroprevalence have been reported among HCWs, but the comparisons are undermined by the difficulty to distinguish the role of occupational risks to that related to the underlying SARS-CoV-2 infection community prevalence [52], and this seems to be confirmed by the finding, detected in the present and in previous studies [53,54], that even in the subgroup of HCWs, SARS-CoV-2 antibodies seropositivity is strongly associated to contact with COVID-19 family members/cohabiting rather than with patients and workplace colleagues. The rate of positivity among HCWs found in this study was higher compared to the results of other investigations conducted in Italy among HCWs in hospital settings [23,55], and, interestingly, also compared to that reported in a study conducted in the same area among HCWs working with suspected and confirmed cases of COVID-19 (3.5\%) [22] and in a study conducted in Tuscany (4.1\%) [56] although during the first wave of the pandemic, when, as expected, it was lower compared to the findings in the geographic areas of Brescia [54] and Milan [57] (Lombardy region), where the prevalence of antibodies against SARS-CoV-2 were $8.6 \%$ and $14.3 \%$, respectively.

Within HCWs, physicians showed the lowest seroprevalence, compared to nurses and other HCWs, and this finding is consistent with previous studies conducted in Sweden [18] and Italy [55], where nurses and healthcare assistants were more likely to test positive. Moreover, no significant differences were revealed according to working area, and this result is more controversial, with studies confirming this finding [52,58] and others that found significant associations between working in COVID-19 wards or having had contact with patients with COVID-19 and HCWs' seropositivity [18,59]. Taken together, the results of the present study suggest that the occupational risk might be more related to the specific professional practice rather than to the characteristics of the treated patients and to the workplace. Finally, in contrast with our finding in the overall population, no association with the occurrence COVID-19-compatible symptoms was found with SARSCoV-2 antibodies seropositivity, suggesting stricter diagnostic protocols in symptomatic HCWs as compared to the general population.

The results of this survey should be analyzed bearing in mind that the mechanisms of the immune response to SARS-CoV-2 infection are still unknown in many aspects. Although it has been demonstrated that seroconversion occurs also in asymptomatic subjects [1,3], debate still exists regarding the duration of detectable antibody titers in both symptomatic and asymptomatic individuals $[60,61]$ and whether this persistence is related to the severity of the disease and/or specific characteristics of subjects (comorbidities, age, etc.) [62,63], as well as regarding the protection against upcoming SARS-CoV-2 infections [64]. Despite all these uncertainties, seroprevalence studies represent a very powerful instrument to have an insight in the cumulative spread of SARS-CoV-2 within populations, and in our specific context it has demonstrated that the extent of the circulation has begun to be relevant by the end of summer and has steadily increased through the end of the year. These results provide evidence of the usefulness of repeated seroprevalence surveys that, for the future, should also take into account the effects of the COVID-19 mass vaccination campaign launched in Europe and Italy on 27 December 2020, for the implications they will have on the assessment of the burden of past SARS-CoV-2 infections and the potential for their further spread in the community, particularly the asymptomatic cases or those symptomatic that have been missed by the surveillance based on laboratory confirmed COVID-19 cases, and for monitoring the community coverage for the achievement of the herd immunity threshold. Indeed, recent evidence suggests that extensive immunization against SARS-CoV-2 could slow the spread of the infection $[65,66]$.

Several limitations should be acknowledged in the interpretations of the results of this study. A convenience voluntary sample was recruited, and considerations on external validity are warranted, since the effect of the willingness to participate and the representativeness of the recruited population on seroprevalence estimates are difficult to establish. However, the peculiar setting that was investigated might allow us to con- 
sider the seroprevalence as representative of the entire population of HCWs in our area, and the remaining sample as representative of the adults in Southern Italy. Nevertheless, confirmation of these seroprevalence estimates through a probabilistic representative sample would be useful. Moreover, serologic tests are subjected to errors with false-positive or false-negative results, with the false positives being of more concern in populations with an expected low seroprevalence. However, the declared sensitivity and specificity of the involved tests were very high, and we may be confident that the false positives and negatives were not numerous enough to have a relevant influence on the final seroprevalence estimates. Furthermore, the data on seroprevalence relied on the use of different types of tests, that might have influenced the results; nonetheless, the performances of the tests are claimed to be similar to each other [67-69]. Finally, the cross-sectional nature of the study with the simultaneous assessment of exposures and outcomes provides no evidence of temporal relationships among variables of interest, and the retrospective assessment of self-reported symptoms, as well as of backdated exposures, may be subjected to misclassification.

In conclusion, the results of the study have demonstrated that the SARS-CoV-2 infection is rapidly spreading even in Southern Italy and far beyond the data revealed by COVID-19 cases surveillance, and confirm the substantial role of seroprevalence studies for the assessment of SARS-CoV-2 infection circulation and the potential for further spreading. Repeated seroprevalence surveys are warranted coupled with the evaluation of the effectiveness of the COVID-19 mass vaccination strategy.

Author Contributions: Conceptualization, F.N.; G.D.G.; M.P. and I.F.A.; methodology, F.N.; G.D.G.; M.P. and I.F.A.; validation, F.N.; G.D.G.; M.V.M.; A.M.M.; G.D.; A.A.; M.P. and I.F.A.; formal analysis, F.N.; G.D.G.; M.P. and I.F.A.; investigation, F.N.; G.D.G.; M.V.M.; A.M.M.; G.D.; A.A.; resources, F.N.; G.D.G.; A.M.M.; G.D.; A.A.; M.P. and I.F.A.; data curation, F.N.; G.D.G.; M.P. and I.F.A.; writingoriginal draft preparation, F.N.; G.D.G.; M.P. and I.F.A.; writing-review and editing, M.P. and I.F.A.; visualization, M.P. and I.F.A.; supervision, M.P. and I.F.A.; project administration, F.N.; G.D.G.; M.P. and I.F.A. All authors have read and agreed to the published version of the manuscript.

Funding: This research received no external funding.

Institutional Review Board Statement: The study was conducted according to the guidelines of the Declaration of Helsinki and approved by the Ethics Committee of the Teaching Hospital of the University of Campania “Luigi Vanvitelli" (protocol code: 1440).

Informed Consent Statement: Informed consent was obtained from all subjects involved in the study.

Data Availability Statement: The data presented in this study are available on request from the corresponding author.

Conflicts of Interest: The authors declare no conflict of interest.

\section{References}

1. Kimball, A.; Hatfield, K.M.; Arons, M.; James, A.; Taylor, J.; Spicer, K.; Bardossy, A.C.; Oakley, L.P.; Tanwar, S.; Chisty, Z.; et al. Asymptomatic and presymptomatic SARS-CoV-2 infections in residents of a long-term care skilled nursing facility-King County, Washington, March 2020. Morb. Mortal. Wkly. Rep. 2020, 69, 377-381. [CrossRef]

2. Mizumoto, K.; Kagaya, K.; Zarebski, A.; Chowell, G. Estimating the asymptomatic proportion of coronavirus disease 2019 (COVID-19) cases on board the Diamond Princess cruise ship, Yokohama, Japan. Euro. Surveill. 2020, 25, 2000180. [CrossRef] [PubMed]

3. Nishiura, H.; Kobayashi, T.; Miyama, T.; Suzuki, A.; Jung, S.M.; Hayashi, K.; Kinoshita, R.; Yang, Y.; Yuan, B. Estimation of the asymptomatic ratio of novel coronavirus infections (COVID-19). Int. J. Infect. Dis. 2020, 94, 154-155. [CrossRef]

4. Furukawa, N.W.; Brooks, J.T.; Sobel, J. Evidence supporting transmission of Severe Acute Respiratory Syndrome Coronavirus 2 while presymptomatic or asymptomatic. Emerg. Infect. Dis. 2020, 26, e201595. [CrossRef]

5. Huang, L.; Zhang, X.; Zhang, X.; Wei, Z.; Zhang, L.; Xu, J.; Liang, P.; Xu, Y.; Zhang, C.; Xu, A. Rapid asymptomatic transmission of COVID-19 during the incubation period demonstrating strong infectivity in a cluster of youngsters aged 16-23 years outside Wuhan and characteristics of young patients with COVID-19: A prospective contact-tracing study. J. Infect. 2020, 80, e1-e13. [CrossRef] [PubMed] 
6. Rothe, C.; Schunk, M.; Sothmann, P.; Bretzel, G.; Froeschl, G.; Wallrauch, C.; Zimmer, T.; Thiel, V.; Janke, C.; Guggemos, W.; et al. Transmission of 2019-nCoV infection from an asymptomatic contact in Germany. N. Engl. J. Med. 2020, 382, 970-971. [CrossRef] [PubMed]

7. Lai, C.C.; Wang, J.H.; Hsueh, P.R. Population-based seroprevalence surveys of anti-SARS-CoV-2 antibody: An up-to-date review. Int. J. Infect. Dis. 2020, 101, 314-322. [CrossRef] [PubMed]

8. Naranbhai, V.; Chang, C.C.; Beltran, W.F.G.; Miller, T.E.; Astudillo, M.G.; Villalba, J.A.; Yang, D.; Gelfand, J.; Bernstein, B.E.; Feldman, J.; et al. High seroprevalence of anti-SARS-CoV-2 antibodies in Chelsea, Massachusetts. J. Infect. Dis. 2020, 222, 1955-1959. [CrossRef]

9. Pollan, M.; Perez-Gomez, B.; Pastor-Barriuso, R.; Oteo, J.; Hernan, M.A.; Perez-Olmeda, M.; Sanmartín, J.L.; Fernández-García, A.; Cruz, I.; Fernández de Larrea, N.; et al. Prevalence of SARS-CoV-2 in Spain (ENE-COVID): A nationwide, population-based seroepidemiological study. Lancet 2020, 396, 535-544. [CrossRef]

10. Sood, N.; Simon, P.; Ebner, P.; Eichner, D.; Reynolds, J.; Bendavid, E.; Bhattacharya, J. Seroprevalence of SARS-CoV-2-specific antibodies among adults in Los Angeles County, California, on 10-11 April 2020. JAMA 2020, 323, 2425-2427. [CrossRef]

11. Stringhini, S.; Wisniak, A.; Piumatti, G.; Azman, A.S.; Lauer, S.A.; Baysson, H.; De Ridder, D.; Petrovic, D.; Schrempft, S.; Marcus, K.; et al. Seroprevalence of anti-SARS-CoV-2 IgG antibodies in Geneva, Switzerland (SEROCoV-POP): A population-based study. Lancet 2020, 396, 313-319. [CrossRef]

12. Xu, X.; Sun, J.; Nie, S.; Li, H.; Kong, Y.; Liang, M.; Hou, J.; Huang, X.; Li, D.; Ma, T.; et al. Seroprevalence of immunoglobulin M and $G$ antibodies against SARS-CoV-2 in China. Nat. Med. 2020, 26, 1193-1195. [CrossRef] [PubMed]

13. Chen, Y.; Tong, X.; Wang, J.; Huang, W.; Yin, S.; Huang, R.; Yang, H.; Chen, Y.; Huang, A.; Liu, Y.; et al. High SARS-CoV-2 antibody prevalence among healthcare workers exposed to COVID-19 patients. J. Infect. 2020, 81, 420-426. [CrossRef] [PubMed]

14. Fischer, B.; Knabbe, C.; Vollmer, T. SARS-CoV-2 IgG seroprevalence in blood donors located in three different federal states, Germany, March to June 2020. Euro. Surveill. 2020, 25, 2001285. [CrossRef]

15. Tsitsilonis, O.E.; Paraskevis, D.; Lianidou, E.; Pierros, V.; Akalestos, A.; Kastritis, E.; Moutsatsou, P.; Scorilas, A.; Sphicopoulos, T.; Terpos, E.; et al. Seroprevalence of antibodies against SARS-CoV-2 among the personnel and students of the National and Kapodistrian University of Athens, Greece: A preliminary report. Life 2020, 10, 214. [CrossRef]

16. Figueiredo-Campos, P.; Blankenhaus, B.; Mota, C.; Gomes, A.; Serrano, M.; Ariotti, S.; Costa, C.; Nunes-Cabaço, H.; Mendes, A.M.; Gaspar, P.; et al. Seroprevalence of anti-SARS-CoV-2 antibodies in COVID-19 patients and healthy volunteers up to 6 months post disease onset. Eur. J. Immunol. 2020, 50, 2025-2040. [CrossRef]

17. Fuereder, T.; Berghoff, A.S.; Heller, G.; Haslacher, H.; Perkmann, T.; Strassl, R.; Berger, J.M.; Puhr, H.C.; Kreminger, J.; Moik, F.; et al. SARS-CoV-2 seroprevalence in oncology healthcare professionals and patients with cancer at a tertiary care centre during the COVID-19 pandemic. ESMO Open 2020, 5, e000889. [CrossRef]

18. Rudberg, A.S.; Havervall, S.; Månberg, A.; Jernbom Falk, A.; Aguilera, K.; Ng, H.; Gabrielsson, L.; Salomonsson, A.C.; Hanke, L.; Murrell, B.; et al. SARS-CoV-2 exposure, symptoms and seroprevalence in healthcare workers in Sweden. Nat. Commun. 2020, 11, 5064. [CrossRef]

19. Nioi, M.; Napoli, P.E.; Lobina, J.; Fossarello, M.; d'Aloja, E. COVID-19 and Italian healthcare workers from the initial sacrifice to the mRNA vaccine: Pandemic chrono-history, epidemiological data, ethical dilemmas, and future challenges. Front. Public Health 2021, 8, 591900. [CrossRef]

20. Decreto del Presidente del Consiglio dei Ministri del 3 novembre 2020. Available online: https:/ /www.gazzettaufficiale.it/eli/ $\mathrm{gu} / 2020 / 11 / 04 / 275 / \mathrm{so} / 41 / \mathrm{sg} / \mathrm{pdf}$ (accessed on 19 April 2021).

21. Cento, V.; Alteri, C.; Merli, M.; Di Ruscio, F.; Tartaglione, L.; Rossotti, R.; Travi, G.; Vecchi, M.; Raimondi, A.; Nava, A.; et al. Effectiveness of infection-containment measures on SARS-CoV-2 seroprevalence and circulation from May to July 2020, in Milan, Italy. PLoS ONE 2020, 15, e0242765. [CrossRef]

22. Fusco, F.M.; Pisaturo, M.; Iodice, V.; Bellopede, R.; Tambaro, O.; Parrella, G.; Di Flumeri, G.; Viglietti, R.; Pisapia, R.; Carleo, M.A.; et al. COVID-19 among healthcare workers in a specialist infectious diseases setting in Naples, Southern Italy: Results of a cross-sectional surveillance study. J. Hosp. Infect. 2020, 105, 596-600. [CrossRef] [PubMed]

23. Paradiso, A.V.; De Summa, S.; Silvestris, N.; Tommasi, S.; Tufaro, A.; De Palma, G.; Larocca, A.M.V.; D'Addabbo, V.; Raffaele, D.; Cafagna, V.; et al. COVID-19 screening and monitoring of asymptomatic health workers with a rapid serological test. medRxiv 2020. Available online: https: / www.medrxiv.org/content/10.1101/2020.05.05.20086017v1 (accessed on 7 February 2021). [CrossRef]

24. Percivalle, E.; Cambiè, G.; Cassaniti, I.; Nepita, E.V.; Maserati, R.; Ferrari, A.; Di Martino, R.; Isernia, P.; Mojoli, F.; Bruno, R.; et al. Prevalence of SARS-CoV-2 specific neutralising antibodies in blood donors from the Lodi Red Zone in Lombardy, Italy, as at 6 April 2020. Euro. Surveill. 2020, 25, 2001031. [CrossRef]

25. Vena, A.; Berruti, M.; Adessi, A.; Blumetti, P.; Brignole, M.; Colognato, R.; Gaggioli, G.; Giacobbe, D.R.; Bracci-Laudiero, L.; Magnasco, L.; et al. Prevalence of antibodies to SARS-CoV-2 in Italian adults and associated risk factors. J. Clin. Med. 2020, 9 , 2780. [CrossRef]

26. Di Giuseppe, G.; Pelullo, C.P.; Della Polla, G.; Pavia, M.; Angelillo, I.F. Exploring the willingness to accept SARS-CoV-2 vaccine in a University population in Southern Italy, September to November 2020. Vaccines 2021, 9, 275. [CrossRef]

27. Di Giuseppe, G.; Pelullo, C.P.; Della Polla, G.; Montemurro, M.V.; Napolitano, F.; Pavia, M.; Angelillo, I.F. Surveying willingness towards SARS-CoV-2 vaccination of healthcare workers in Italy. Exp. Rev. Vacc. 2021. Available online: https://www.tandfonline. com/doi/abs/10.1080/14760584.2021.1922081?journalCode=ierv20 (accessed on 28 April 2021). [CrossRef] 
28. Stata Corporation. Stata Reference Manual Release 15.1; Stata Corporation: College Station, TX, USA, 2017.

29. Ministero della Salute-Istituto Nazionale di Statistica. Primi Risultati Dell'indagine di Sieroprevalenza sul SARS-CoV-2. Available online: https: / / www.istat.it/it/ files/ / 2020/08/ReportPrimiRisultatiIndagineSiero.pdf (accessed on 7 February 2021).

30. Gallian, P.; Pastorino, B.; Morel, P.; Chiaroni, J.; Ninove, L.; de Lamballerie, X. Lower prevalence of antibodies neutralizing SARS-CoV-2 in group O French blood donors. Antivir. Res. 2020, 181, 104880. [CrossRef]

31. Fiore, J.R.; Centra, M.; De Carlo, A.; Granato, T.; Rosa, A.; Sarno, M.; De Feo, L.; Di Stefano, M.; Errico, M.; Caputo, S.L.; et al. Results from a survey in healthy blood donors in South Eastern Italy indicate that we are far away from herd immunity to SARS-CoV-2. J. Med. Virol. 2020, 93, 1739-1742. [CrossRef] [PubMed]

32. Tilley, K.; Ayvazyan, V.; Martinez, L.; Nanda, N.; Kawaguchi, E.S.; O'Gorman, M.; Conti, D.; Gauderman, W.J.; Van Orman, S. A cross-sectional study examining the seroprevalence of Severe Acute Respiratory Syndrome Coronavirus 2 antibodies in a university student population. J. Adolesc. Health 2020, 67, 763-768. [CrossRef] [PubMed]

33. Tuells, J.; Egoavil, C.M.; Pena Pardo, M.A.; Montagud, A.C.; Montagud, E.; Caballero, P.; Zapater, P.; Puig-Barberá, J.; HurtadoSanchez, J.A. Seroprevalence study and cross-sectional survey on COVID-19 for a plan to reopen the University of Alicante (Spain). Int. J. Environ. Res. Public Health 2021, 18, 1908. [CrossRef]

34. Torres, J.P.; Piñera, C.; De La Maza, V.; Lagomarcino, A.J.; Simian, D.; Torres, B.; Urquidi, C.; Valenzuela, M.T.; O’Ryan, M. SARSCoV-2 antibody prevalence in blood in a large school community subject to a Covid-19 outbreak: A cross-sectional study. Clin. Infect. Dis 2020, ciaa955. Available online: https://academic.oup.com/cid/advance-article/doi/10.1093/cid/ciaa955/5869860 (accessed on 7 April 2021). [CrossRef]

35. Arnold, C.R.K.; Srinivasan, S.; Herzog, C.M.; Gontu, A.; Bharti, N.; Small, M.; Rogers, C.J.; Schade, M.M.; Kuchipudi, S.V.; Kapur, V.; et al. SARS-CoV-2 Seroprevalence in a University Community: A longitudinal study of the impact of student return to campus on infection risk among community members. medRxiv 2021. Available online: https://www.medrxiv.org/content/10.1101/2021 .02.17.21251942v3 (accessed on 7 April 2021). [CrossRef]

36. Havers, F.P.; Reed, C.; Lim, T.; Montgomery, J.M.; Klena, J.D.; Hall, A.J.; Fry, A.M.; Cannon, D.L.; Chiang, C.F.; Gibbons, A.; et al. Seroprevalence of Antibodies to SARS-CoV-2 in 10 sites in the United States, 23 March-12 May 2020. JAMA Intern. Med. 2020, 180, 1576-1586. [CrossRef]

37. Adams, M.L.; Katz, D.L.; Grandpre, J. Population-based estimates of chronic conditions affecting risk for complications from Coronavirus Disease, United States. Emerg. Infect. Dis. 2020, 26, 1831-1833. [CrossRef]

38. Jain, V.; Yuan, J. Predictive symptoms and comorbidities for severe COVID-19 and intensive care unit admission: A systematic review and meta-analysis. Int. J. Public Health 2020, 65, 533-546. [CrossRef]

39. Seidu, S.; Gillies, C.; Zaccardi, F.; Kunutsor, S.K.; Hartmann-Boyce, J.; Yates, T.; Singh, A.K.; Davies, M.J.; Khunti, K. The impact of obesity on severe disease and mortality in people with SARS-CoV-2: A systematic review and meta-analysis. Endocrinol. Diabetes Metab. 2020, 4, e00176. [CrossRef] [PubMed]

40. Singh, A.K.; Gillies, C.L.; Singh, R.; Singh, A.; Chudasama, Y.; Coles, B.; Seidu, S.; Zaccardi, F.; Davies, M.J.; Khunti, K. Prevalence of co-morbidities and their association with mortality in patients with COVID-19: A systematic review and meta-analysis. Diabetes Obes. Metab. 2020, 22, 1915-1924. [CrossRef]

41. Fakhroo, A.D.; Al Thani, A.A.; Yassine, H.M. Markers associated with COVID-19 susceptibility, resistance, and severity. Viruses 2020, 13, 45. [CrossRef]

42. Ghoneim, S.; Butt, M.U.; Hamid, O.; Shah, A.; Asaad, I. The incidence of COVID-19 in patients with metabolic syndrome and non-alcoholic steatohepatitis: A population-based study. Metabol. Open 2020, 8, 100057. [CrossRef] [PubMed]

43. Hernández-Garduño, E. Obesity is the comorbidity more strongly associated for Covid-19 in Mexico. A case-control study. Obes. Res. Clin. Pract. 2020, 14, 375-379. [CrossRef] [PubMed]

44. Jung, C.Y.; Park, H.; Kim, D.W.; Lim, H.; Chang, J.H.; Choi, Y.J.; Kim, S.W.; Chang, T.I. Association between Body Mass Index and risk of COVID-19: A nationwide case-control study in South Korea. Clin. Infect. Dis. 2020, ciaa1257. Available online: https:/ / academic.oup.com/cid/advance-article/doi/10.1093/cid/ciaa1257/5897045 (accessed on 7 April 2021). [CrossRef]

45. Popkin, B.M.; Du, S.; Green, W.D.; Beck, M.A.; Algaith, T.; Herbst, C.H.; Alsukait, R.F.; Alluhidan, M.; Alazemi, N.; Shekar, M. Individuals with obesity and COVID-19: A global perspective on the epidemiology and biological relationships. Obes. Rev. 2020, 21, e13128. [CrossRef] [PubMed]

46. Vos, E.R.A.; den Hartog, G.; Schepp, R.M.; Kaaijk, P.; van Vliet, J.; Helm, K.; Smits, G.; Wijmenga-Monsuur, A.; Verberk, J.D.M.; van Boven, M.; et al. Nationwide seroprevalence of SARS-CoV-2 and identification of risk factors in the general population of the Netherlands during the first epidemic wave. J. Epidemiol. Community Health 2020. Available online: https: //jech.bmj.com/content/early/2020/11/28/jech-2020-215678.long (accessed on 28 April 2021). [CrossRef] [PubMed]

47. Barzin, A.; Schmitz, J.L.; Rosin, S.; Sirpal, R.; Almond, M.; Robinette, C.; Wells, S.; Hudgens, M.; Olshan, A.; Deen, S.; et al. SARS-CoV-2 seroprevalence among a Southern U.S. population indicates limited asymptomatic spread under physical distancing measures. mBio 2020, 11, e02426-20. [CrossRef] [PubMed]

48. Al-Shamsi, H.O.; Alhazzani, W.; Alhuraiji, A.; Coomes, E.A.; Chemaly, R.F.; Almuhanna, M.; Wolff, R.A.; Ibrahim, N.K.; Chua, M.L.K.; Hotte, S.J.; et al. A practical approach to the management of cancer patients during the Novel Coronavirus Disease 2019 (COVID-19) pandemic: An International Collaborative Group. Oncologist 2020, 25, e936-e945. [CrossRef] 
49. Maringe, C.; Spicer, J.; Morris, M.; Purushotham, A.; Nolte, E.; Sullivan, R.; Rachet, B.; Aggarwal, A. The impact of the COVID-19 pandemic on cancer deaths due to delays in diagnosis in England, UK: A national, population-based, modelling study. Lancet Oncol. 2020, 21, 1023-1034. [CrossRef]

50. Napoli, P.E.; Nioi, M.; d'Aloja, E.; Fossarello, M. Safety recommendations and medical liability in ocular surgery during the COVID-19 pandemic: An unsolved dilemma. J. Clin. Med. 2020, 9, 1403. [CrossRef]

51. Wong, J.S.H.; Cheung, K.M.C. Impact of COVID-19 on orthopaedic and trauma service: An epidemiological study. J. Bone Joint Surg. Am. 2020, 102, e80. [CrossRef]

52. Dimcheff, D.E.; Schildhouse, R.J.; Hausman, M.S.; Vincent, B.M.; Markovitz, E.; Chensue, S.W.; Deng, J.; McLeod, M.; Hagan, D.; Russell, J.; et al. Seroprevalence of severe acute respiratory syndrome coronavirus-2 (SARS-CoV-2) infection among Veterans Affairs healthcare system employees suggests higher risk of infection when exposed to SARS-CoV-2 outside the work environment. Infect. Control Hosp. Epidemiol. 2021, 42, 392-398. [CrossRef]

53. Steensels, D.; Oris, E.; Coninx, L.; Nuyens, D.; Delforge, M.L.; Heylen, L. Hospital-wide SARS-CoV-2 antibody screening in 3056 staff in a tertiary center in Belgium. JAMA 2020, 324, 195-197. [CrossRef]

54. Paderno, A.; Fior, M.; Berretti, G.; Schreiber, A.; Grammatica, A.; Mattavelli, D.; Deganello, A. SARS-CoV-2 infection in health care workers: Cross-sectional analysis of an otolaryngology unit. Otolaryngol. Head Neck Surg. 2020, 163, 671-672. [CrossRef] [PubMed]

55. Plebani, M.; Padoan, A.; Fedeli, U.; Schievano, E.; Vecchiato, E.; Lippi, G.; Lo Cascio, G.; Porru, S.; Palù, G. SARS-CoV-2 serosurvey in health care workers of the Veneto Region. Clin. Chem. Lab. Med. 2020, 58, 2107-2111. [CrossRef] [PubMed]

56. Lastrucci, V.; Lorini, C.; Del Riccio, M.; Gori, E.; Chiesi, F.; Sartor, G.; Zanella, B.; Boccalini, S.; Bechini, A.; Puggelli, F.; et al. SARS-CoV-2 seroprevalence survey in people involved in different essential activities during the general lock-down phase in the province of Prato (Tuscany, Italy). Vaccines 2020, 8, 778. [CrossRef]

57. Sotgiu, G.; Barassi, A.; Miozzo, M.; Saderi, L.; Piana, A.; Orfeo, N.; Colosio, C.; Felisati, G.; Davì, M.; Gerli, A.G.; et al. SARS-CoV-2 specific serological pattern in healthcare workers of an Italian COVID-19 forefront hospital. BMC Pulm. Med. 2020, $20,203$. [CrossRef]

58. Martin, C.; Montesinos, I.; Dauby, N.; Gilles, C.; Dahma, H.; Van Den Wijngaert, S.; De Wit, S.; Delforge, M.; Clumeck, N.; Vandenberg, O. Dynamics of SARS-CoV-2 RT-PCR positivity and seroprevalence among high-risk healthcare workers and hospital staff. J. Hosp. Infect. 2020, 106, 102-106. [CrossRef] [PubMed]

59. Iversen, K.; Bundgaard, H.; Hasselbalch, R.B.; Kristensen, J.H.; Nielsen, P.B.; Pries-Heje, M.; Knudsen, A.D.; Christensen, C.E.; Fogh, K.; Norsk, J.B.; et al. Risk of COVID-19 in health-care workers in Denmark: An observational cohort study. Lancet Infect. Dis. 2020, 20, 1401-1408. [CrossRef]

60. Gudbjartsson, D.F.; Norddahl, G.L.; Melsted, P.; Gunnarsdottir, K.; Holm, H.; Eythorsson, E.; Arnthorsson, A.O.; Helgason, D.; Bjarnadottir, K.; Ingvarsson, R.F.; et al. Humoral immune response to SARS-CoV-2 in Iceland. N. Engl. J. Med. 2020, 383, 1724-1734. [CrossRef]

61. Ibarrondo, F.J.; Fulcher, J.A.; Goodman-Meza, D.; Elliott, J.; Hofmann, C.; Hausner, M.A.; Ferbas, K.G.; Tobin, N.H.; Aldrovandi, G.M.; Yang, O.O. Rapid decay of Anti-SARS-CoV-2 antibodies in persons with mild Covid-19. N. Engl. J. Med. 2020, 383, 1085-1087. [CrossRef] [PubMed]

62. Long, Q.X.; Tang, X.J.; Shi, Q.L.; Li, Q.; Deng, H.J.; Yuan, J.; Hu, J.L.; Xu, W.; Zhang, Y.; Lv, F.J.; et al. Clinical and immunological assessment of asymptomatic SARS-CoV-2 infections. Nat. Med. 2020, 26, 1200-1204. [CrossRef]

63. To, K.K.; Tsang, O.T.; Leung, W.S.; Tam, A.R.; Wu, T.C.; Lung, D.C.; Yip, C.C.; Cai, J.P.; Chan, J.M.; Chik, T.S.; et al. Temporal profiles of viral load in posterior oropharyngeal saliva samples and serum antibody responses during infection by SARS-CoV-2: An observational cohort study. Lancet Infect. Dis. 2020, 20, 565-574. [CrossRef]

64. GeurtsvanKessel, C.H.; Okba, N.M.A.; Igloi, Z.; Bogers, S.; Embregts, C.W.E.; Laksono, B.M.; Leijten, L.; Rokx, C.; Rijnders, B.; Rahamat-Langendoen, J.; et al. An evaluation of COVID-19 serological assays informs future diagnostics and exposure assessment. Nat. Commun. 2020, 11, 3436. [CrossRef] [PubMed]

65. Levine-Tiefenbrun, M.; Yelin, I.; Katz, R.; Herzel, E.; Golan, Z.; Schreiber, L.; Wolf, T.; Nadler, V.; Ben-Tov, A.; Kuint, J.; et al. Initial report of decreased SARS-CoV-2 viral load after inoculation with the BNT162b2 vaccine. Nat. Med. 2021. Available online: https:/ / www.nature.com/articles/s41591-021-01316-7 (accessed on 7 April 2021). [CrossRef] [PubMed]

66. Thompson, M.G.; Burgess, J.L.; Naleway, A.L.; Tyner, H.L.; Yoon, S.K.; Meece, J.; Olsho, L.E.W.; Caban-Martinez, A.J.; Fowlkes, A.; Lutrick, K.; et al. Interim estimates of vaccine effectiveness of BNT162b2 and mRNA-1273 COVID-19 vaccines in preventing SARS-CoV-2 infection among health care personnel, first responders, and other essential and frontline workers-Eight U.S. locations, December 2020-March 2021. Morb. Mortal. Wkly. Rep. 2021, 70, 495-500.

67. Brochot, E.; Demey, B.; Handala, L.; François, C.; Duverlie, G.; Castelain, S. Comparison of different serological assays for SARS-CoV-2 in real life. J. Clin. Virol. 2020, 130, 104569. [CrossRef]

68. Jääskeläinen, A.J.; Kuivanen, S.; Kekäläinen, E.; Loginov, R.; Kallio-Kokko, H.; Vapalahti, O.; Jarva, H.; Kurkela, S.; Lappalainen, M. Performance of six SARS-CoV-2 immunoassays in comparison with microneutralisation. J. Clin. Virol. 2020, $129,104512$. [CrossRef] [PubMed]

69. Theel, E.S.; Harring, J.; Hilgart, H.; Granger, D. Performance characteristics of four high-throughput immunoassays for detection of IgG antibodies against SARS-CoV-2. J. Clin. Microbiol. 2020, 58, e01243-20. [CrossRef] [PubMed] 